\title{
World Health Organization simulations: an increasingly popular learning tool for the development of future global health practitioners
}

\author{
Brian LH Wong ${ }^{*}$, Mark P Khurana ${ }^{2 *}$, Neha Acharya ${ }^{3}$, Michalina Drejza ${ }^{4}$, \\ Diogo Martins ${ }^{4}$
}

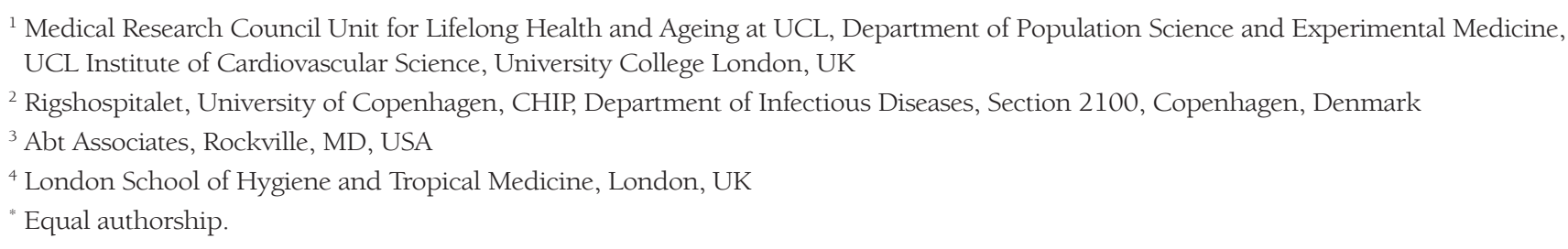

WHO simulations provide SYPs with experiential learning environments to engage with global health issues, undertake research and partake in negotiations surrounding global health policy.
工 nterest among students and young professionals (SYPs) in global health is undoubtedly on the rise $[1,2]$. Novel methods for increasing engagement of SYPs with the field are imperative. An increasingly interconnected and globalized world poses an array of new health challenges, including a rising burden of NCDs, the rapid movement of communicable diseases and threats to global health security. Such pressing issues demand that future health professionals develop a more holistic and interdisciplinary understanding of health and the necessary critical skills of policy-making, negotiation, and conflict-resolution. To quote Professor Ilona Kickbusch of the Graduate Institute of International and Development Studies in Geneva, "global health diplomacy is gaining in importance and its negotiators should be well prepared" [3]. One such initiative with this ethos and which provides this cadre of proficiencies is student-led Model World Health Organization (WHO) simulations.

\section{SIMULATIONS AS A LEARNING TOOL}

Model WHO simulations recreate the proceedings of the World Health Assembly (WHA), the decision-making body of the WHO, which takes place annually in Geneva, Switzerland. In these simulations, participants discuss topics within a pre-defined theme for the conference (Table 1); previous themes include Sexual Health; Women's, Children's and Adolescents' Health; and Environmental Health. Simulation participants are designated roles from a diverse list of stakeholders: Member States, Non-State Actors (NSAs) - such as non-governmental organizations or private sector representatives, UN Agencies and Media/ Press. Member State representatives discuss and negotiate policy papers, initially within their given WHO region [4], and later collectively in plenary. During plenary sessions, all participants assemble to merge 
Table 1. List of locations with student-run Model World Health Organization Simulations in 2018, themes and attendance

\begin{tabular}{|c|c|c|c|}
\hline ReeloN & LOCATION & THEME & AtTENDANCE \\
\hline \multirow[t]{4}{*}{ Europe } & London & Improving the Health of Women, Children and Adolescents & 175 \\
\hline & Paris & Environmental Health & 120 \\
\hline & Copenhagen & Access to essential medicines - How can we ensure global equality? & 80 \\
\hline & Sheffield & Outbreaks and Pandemics: Addressing the Next Crisis & 87 \\
\hline \multirow[t]{8}{*}{ North America } & Montreal & Health Crises & 80 \\
\hline & Toronto & Sexual Health & 50 \\
\hline & Edmonton & Organ Trade \& Trafficking & 35 \\
\hline & Newfoundland and Labrador & Critical and Acute Care & 63 \\
\hline & Chapel Hill, North Carolina & Global Health Innovation: Novel Idea, New Horizons & 112 \\
\hline & Blacksburg, Virginia & Vaccines & 65 \\
\hline & Norman, Oklahoma & Impacting Health Through Education & 83 \\
\hline & Baltimore, Maryland & Social Sustainability & 71 \\
\hline Australia & Melbourne & Mental Health: Beyond the Stigma & 65 \\
\hline Asia & Tokyo & $\begin{array}{l}\text { Creating International Health Regulations for Emerging and } \\
\text { Re-emerging Infectious Diseases }\end{array}$ & 50 \\
\hline
\end{tabular}

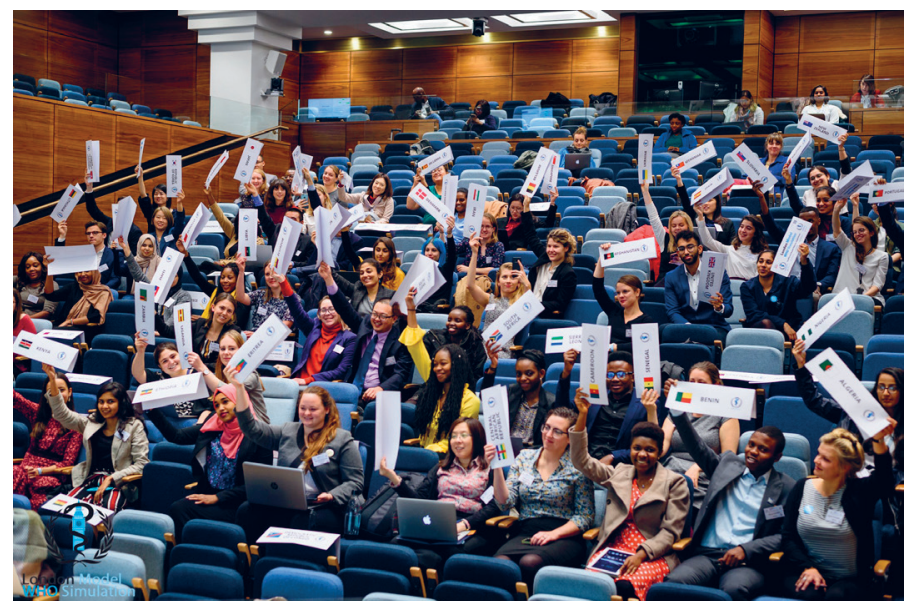

Photo: from the 2019 LonWHO conference, held at Bush House, King's College, London (from the collection of Charlie Harless, used with permission).
Simulations complement other creative learning modules in global health such as MOOCs, webinars and social media initiatives.

and amend draft resolutions, with the ultimate goal of passing a final conference resolution. Ideally, the final resolution reflects how Member States prioritize and develop solutions to address the overall conference theme - similar to WHO resolutions at the WHA. Throughout the simulation process, NSA representatives seek to influence discussions, offer recommendations, and capture discourse through written/video formats.

\section{ADAPTING TO DIFFERENT FORMATS}

Alternative versions of these simulations have in fact been adopted in other settings. At University College London (UCL), a five-day model WHO simulation has been integrated into the "Outbreak! Infectious Diseases" strand of the annual UCL Global Citizenship Program [5]. In addition, at the biennial Young Leaders for Health (YLH) conference in Berlin, a WHO simulation has been included in the official conference program since 2015 [6]. To cater to the growing interest in these types of simulations, regional organizations have been established to standardize simulation formats and promote knowledge-sharing between simulation organizers; these include the American Mock World Health Organization (AMWHO) and the United Kingdom Model World Health Organization (UKWHO) $[7,8]$.

\section{CREATIVE MODULES IN GLOBAL HEALTH}

These conferences provide SYPs with experiential learning environments to engage with global health issues, undertake research, and partake in negotiations surrounding global health policy. At the most recent WHO simulation in London, Lon WHO ( $\mathrm{n}=87$ responses), $87.4 \%$ of participants considered a career in global public health prior to the conference compared to $96.6 \%$ after the conference. In a similar vein, $98.9 \%$ of participants would recommend the conference to peers. Model WHO simulations also have the capacity to complement other creative learning modules in global health such as MOOCs, webinars, and 
social media initiatives [9]. Furthermore, they allow for SYPs from all disciplines - spanning from nursing to health economics to political science - to engage in stimulating debate, fostering a truly interdisciplinary approach to health in true WHO spirit. In doing so, simulations allow for innovative and collaborative thinking to surface, whilst providing SYPs with a more practical and real-world experience in global health diplomacy to complement standardized taught curricula. Promotion and expansion of creative learning modules such as WHO simulations, both in terms of volume and geographic reach, has the potential to inspire and engage future global health practitioners in developing the necessary technical knowledge and soft skills essential for global health diplomacy.

\footnotetext{
Acknowledgements: Thanks to Dr Hareen De Silva for input regarding the manuscript.
Funding: No funding to declare.
Authorship contributions: BLHW, MPK and NA were responsible for data collection. All authors have contribut-
ed equally to the writing of the main manuscript.
Competing interests: The authors completed the ICMJ Unified Competing Interest form at (available upon request
from the corresponding author), and declare no further conflicts of interest. The corresponding author has full ac-
cess to all the data and has final responsibility for the decision to submit for publication.
}

1 Nelson BD, Kasper J, Hibberd P, Thea D, Herlihy J. Developing a Career in Global Health: Considerations for Physicians-in-Training and Academic Mentors. J Grad Med Educ. 2012;4:301-6. Medline:23997872 doi:10.4300/ JGME-D-11-00299.1

2 Drain PK, Holmes K, Skeff K, Hall T, Gardner P. Global Health Training and International Clinical Rotations During Residency: Current Status, Needs, and Opportunities. Acad Med. 2009;84:320-5. Medline:19240438 doi:10.1097/ ACM.0b013e3181970a37

3 Kickbusch I, Silberschmidt G, Buss P. Global health diplomacy: the need for new perspectives, strategic approaches and skills in global health. Bull World Health Organ. 2007;85:230-2. Medline:17486216 doi:10.2471/BLT.06.039222

4 World Health Organization regional offices. 2019. Available: https://www.who.int/about/who-we-are/regional-offices. Accessed: 30 April 2019

5 Outbreak UCL. Infectious Diseases. UCL Global Citizenship Programme. 2019. Available: https://www.ucl.ac.uk/global-citizenship-programme/right-strand-for-me/outbreak. Accessed: 19 November 2019.

6 Young Leaders for Health. YLH Conference 2015. Available: https://www.youngleadersforhealth.org/conference. Accessed: 19 November 2019.

7 Lei M, Acharya N, Lee EKM, Holcomb EC, Kapoor V. American Mock World Health Organization: An Innovative Model for Student Engagement in Global Health Policy. GHSP. 2017;5:164-74. Medline:28351883 doi:10.9745/GHSP-D-16-00138

8 UK World Health Organization. About UKWHO. UKWHO (United Kingdom World Health Organization). Available: http://ukwho.org/about-ukwho/. Accessed: 11 November 2019.

9 Jacquet GA, Umoren RA, Hayward AS, Myers JG, Modi P, Dunlop SJ, et al. The Practitioner's Guide to Global Health: an interactive, online, open-access curriculum preparing medical learners for global health experiences. Med Educ Online. 2018;23:1503914. Medline:30081760 doi:10.1080/10872981.2018.1503914

\section{Correspondence to:}

Brian L.H. Wong, MSc

Medical Research Council Unit for Lifelong

Health and Ageing at UCL

Department of Population Science and Experimental Medicine

UCL Institute of Cardiovascular Science

University College London

5th Floor, 1-19 Torrington Place, Fitzrovia

London, UK WC1E 7HB

b.wong@ucl.ac.uk 